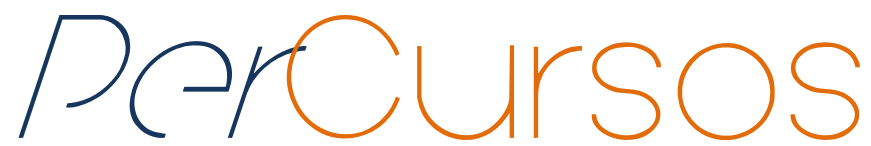

\title{
Educação das relações étnico-raciais na educação infantil: uma proposta, múltiplas possibilidades
}

\begin{abstract}
Resumo
Este artigo apresenta uma discussão acerca da Educação das Relações Étnico-Raciais na Educação de crianças de zero a seis anos de idade, procurando trazer algumas ações e propostas vivenciadas no Projeto de Docência "Em busca de novos paradigmas para a educação: Incorporando práticas para a implementação da Lei Federal 10.639/03 na Educação Infantil", realizado em uma creche da Rede Municipal de Florianópolis/SC. A partir dessa experiência, enfatizamos alguns aspectos que podem ser aprofundados para propiciar o desenvolvimento de ações que contribuam para a implementação da Lei Federal 10.639/03 e das Diretrizes Curriculares Nacionais para a Educação das Relações Étnico-Raciais e para o Ensino de História e Cultura Africana e Afro-Brasileira nas instituições de educação infantil. Pretendemos, com a exposição de reflexões e possibilidades, incentivar os/as educadores/as a efetivarem um trabalho que contemple a diversidade presente nos diferentes âmbitos de nossa sociedade.
\end{abstract}

Palavras-chave: Educação Infantil. Educação das Relações ÉtnicoRaciais. Lei Federal 10.639/03.

\author{
Eduarda Souza Gaudio \\ Mestranda em Educação pelo \\ Programa de Pós Graduação da \\ Universidade Federal de Santa \\ Catarina - UFSC \\ dudasouza_1@hotmail.com
}

\section{Thaís Regina de Carvalho}

Mestrado em educação pela

Universidade Federal do Paraná UFPR.

thatahrc@gmail.com

\section{Para citar este artigo:}

GAUDIO, Eduarda Souza; CARVALHO, Thaís Regina de. Educação das relações étnico-raciais na educação infantil: uma proposta, múltiplas possibilidades. Revista PerCursos. Florianópolis, v. 14, n.26, jan./jun. 2013. p. $40-57$.

\section{DOI: $10.5965 / 198472421426201340$}

http://dx.doi.org/10.5965/198472461426201340 


\title{
Education ethnic-racial relations: a proposal, multiple possibilities
}

\begin{abstract}
This paper aims to present a discussion on the Education of Racial-Ethnic Relations in Education of children aged zero to six years old, looking to bring. Furthermore, this paper presents some proposals and actions experienced in Project Teaching "In search of new paradigms for education: Incorporating practices for the implementation of the Federal Law 10.639/03 in Early Childhood Education" held in a nursery of the Municipal Florianópolis/SC. From this experience, we emphasize some aspects that can be further developed to foster the development of actions that contribute to the implementation of the Federal Law 10639/03 and the National Curriculum Guidelines for the Education of Racial-Ethnic Relations and the Teaching of History and Culture African and AfroBrazilian in early childhood institutions. We intend to exposure of reflections and possibilities, encourage / as educators / them to actualize a work that addresses the diversity present in different aspects of our society.
\end{abstract}

Keywords: Early Childhood Education. Education of Racial-Ethnic Relations. Federal Law 10.639/03. 


\section{Considerações Iniciais}

Após um processo de discussões, movimentos e lutas em torno da educação de meninos e meninas de zero a seis anos de idade, no ano de 1988, o atendimento de creches e pré-escolas foi reconhecido como um direito social de todas as crianças. Com esse progresso, o campo da educação infantil tem passado por intensos debates a respeito das concepções que envolvem infância e crianças, bem como propostas pedagógicas que norteiam o desenvolvimento integral e a aprendizagem de todas as crianças.

Outra área que, embora em alguns casos, de maneira tímida, vem ganhando reconhecimento no âmbito da educação são as relações étnico-raciais, que, desde o ano de 2003, com a homologação da Lei Federal 10.639/03, modifica o artigo 26-A da LDB, tornando obrigatório o ensino de história e cultura africana e afro-brasileira em todas as instituições de ensino. A partir dessa determinação, o âmbito público vem criando documentos e propostas pedagógicas que procuram subsidiar a educação das relações étnico-raciais, contribuindo para a valorização da diversidade étnico-racial e a promoção da igualdade de tratamento de todas as crianças. Nesse debate, as Diretrizes Curriculares Nacionais para a Educação Infantil (2010) trazem como proposta pedagógica para o trabalho coletivo "o reconhecimento, a valorização, o respeito e a interação das crianças com as histórias e as culturas africanas, afro-brasileiras, bem como o combate ao racismo e à discriminação" (BRASIL, 2010, p. 21).

Com base nesses pressupostos, percebemos que a efetivação dessas propostas se apresenta como algo imprescindível a ser considerado nas instituições formais, visto que diversas pesquisas ${ }^{1}$ evidenciam que a existência de práticas e relações pedagógicas homogeneizadoras, preconceituosas e discriminatórias vêm sendo desenvolvidas nos diferentes espaços de educação.

Diante desse contexto, é necessário reconhecer que grande parte da formação inicial e continuada dos/as professores/as não contemplou a Educação das Relações

\footnotetext{
${ }^{1}$ Ver Cavalheiro (2003), Oliveira (2004), Lima (2006), Botega (2006).
} 
Étnico-Raciais, o que torna a implementação do artigo 26-A da LDB (Lei Federal 10639/03) uma difícil tarefa para os/as educadores/as. Além disso, outro fator que interfere nesse trabalho é a acessibilidade aos materiais pedagógicos, devido às más condições de trabalho ou, até mesmo, sua disponibilização. Dessa forma, a bibliografia estudada oferece subsídios às ações pedagógicas dos/as professores/as, bem como à promoção de formações continuadas com estudos e orientações em torno da diversidade étnico-racial e dos pressupostos da educação das relações étnico-raciais.

É nessa perspectiva que surge o presente artigo, o qual busca apresentar possíveis propostas que possam auxiliar a ação docente a partir das demandas da Lei Federal 10.639/03, das Diretrizes Curriculares Nacionais para a Educação das Relações ÉtnicoRaciais e para o Ensino de História e Cultura Africana e Afro-Brasileira e das Diretrizes Curriculares Nacionais para a Educação Infantil (2010), almejando assim contribuir para concretização de ações que contemplem a educação das relações étnico-raciais na educação infantil.

\section{Breves Reflexões sobre Educação Infantil}

Nas duas últimas décadas, a educação infantil - primeira etapa da educação básica e um direito de todas as crianças - vem sendo alvo de muitas discussões e pesquisas que englobam suas peculiaridades. Um exemplo desse debate são as concepções de crianças e infância que sofreram transformações, no sentido de compreendê-las como sujeitos de direitos capazes de elaborar produções culturais na relação com seus pares e adultos. Nessa mesma perspectiva, Nascimento (2011, p. 41) defende que "as crianças pertencem a diferentes classes sociais, ao gênero masculino e feminino, a um espaço geográfico onde residem, à cultura de origem e a uma etnia, em outras palavras, são crianças concretas e contextualizadas, são membros da sociedade [...]”.

Imersas nessa conjuntura, foram criadas pela Secretaria da Educação de Florianópolis/SC no ano de 2010 as “Diretrizes Educacionais Pedagógicas para Educação Infantil”, a qual defendem uma educação das crianças de zero a cinco anos que respeite seus direitos fundamentais e Ihes garanta a formação integral orientada para as 
diferentes dimensões humanas - linguística, intelectual, expressiva, emocional, corporal, social e cultural -, realizando-se através de uma ação intencional, de forma a contemplar cada uma destas dimensões como núcleos da ação pedagógica (FLORIANÓPOLIS, 2010, p. 12).

Dentre os diversos aspectos acerca da educação infantil, salientamos que os ambientes educativos são constituídos por riquezas que necessitam ser consideradas. A grama, a areia, a sala, o refeitório, as músicas, as brincadeiras, as roupas, as crianças, todos esses elementos devem ser explorados para a construção do olhar sensível de todos/as envolvidos/as na instituição de educação infantil. Sobre esse assunto, Dias (1999, p. 200) acrescenta que "a sensibilização estética precisa estar presente na escola para que esta possa ser um espaço de vida, expressão, criação, formação de sujeitos sensíveis, capazes de reinterpretar, transformar, reconstruir a realidade a seu redor". Neste sentido, acreditamos ser essencial trabalhar com nossa sensibilidade, para que, a partir disso, possamos auxiliar as crianças no processo de desenvolvimento máximo das capacidades humanas (MELLO, 2007).

Seguindo estes pressupostos, enfatizamos que as ações voltadas à educação infantil precisam ter como principais protagonistas as crianças, de tal forma que abranjam questões referentes às interações, às múltiplas linguagens e brincadeiras, levando em consideração os princípios éticos, políticos e estéticos ressaltados em muitos documentos públicos que orientam a ação docente do âmbito da educação das crianças pequenas (BRASIL, 2010).

Dando continuidade ao debate, destacamos as contribuições de Corsino (2006), na qual apresenta a linguagem como aspecto fundamental de diferentes brincadeiras transmitidas entre gerações. Segundo a autora, a linguagem é o elemento principal pelo qual realizamos contato com nossa cultura, estabelecemos relações com as pessoas, bem como construímos diferentes significados acerca do mundo em que vivemos. Assim, ela retrata a importância de trabalharmos a linguagem das crianças como artefato essencial à educação infantil. Assim, através de sua interação com o mundo, a criança vai se 
apropriando, gradativamente, da linguagem em suas relações com os objetos e com o outro, seja criança ou adulto.

Dessa forma, acreditamos que os/as educadores/as devem incluir em suas práticas, atividades em que todas as crianças sejam contempladas, considerando as múltiplas infâncias ${ }^{2}$, os diversos brincares, além das manifestações artísticas, pois estas são fundamentais para seu pleno desenvolvimento . Para isso, defendemos que as crianças devem ser aguçadas a experienciar as atividades de expressão, assim como as brincadeiras de faz-de-conta, para disso se apropriar e com isso auxiliar na construção do conhecimento acerca da realidade em que estão inseridas.

Sobre a imaginação e a criação na infância, é essencial trazer as contribuições de Vygotsky (2009), cujos estudos ressaltam que os processos de criação se revelam com maior intensidade na infância, sobretudo durante as brincadeiras. Os atos e as percepções das crianças perante os objetos se desenvolvem e se transformam a partir da combinação de elementos e experiências extraídos da realidade. Portanto, a brincadeira pode ser considerada imaginação em realidade, na qual a criança realiza seus desejos.

Além disso, a imaginação está sempre orientada às experiências dos outros e delas depende diretamente. Por exemplo, se ninguém tivesse visto ou relatado uma revolução, seria difícil conseguir realizar uma representação correta desse fenômeno. Deste modo, é fundamental que os/as professores promovam momentos de narrativa:

[...] É narrando para o outro o que nos aconteceu que a vivência dos fatos perde a finitude do presente e ganha uma nova dimensão, pela possibilidade de continuidade do ouvinte. Criamos laços com o outro quando podemos falar e ouvir, quando nos colocamos e nos vemos no lugar do outro, partilhando as experiências vividas. (CORSINO, 2006, p. 40).

Assim, enfatizamos a importância de ouvir e contar histórias às crianças, desde os bebês, até as meninas e meninos de mais idade. As histórias, além de proporcionar que os

\footnotetext{
${ }^{2}$ Adotamos o conceito de infâncias, no plural, seguindo a perspectiva de que existem várias infâncias, levando em consideração as particularidades vivenciadas por cada criança de acordo com sua classe social, gênero, pertencimento étnico, entre outras diferenças que balizam as infâncias (ABRAMOWICZ, 2011).
} 
indivíduos vivenciem o que o outro experimenta, contribuem para o desenvolvimento da capacidade de ouvir. É essencial, portanto, que se utilizem diferentes recursos como: fantoches, imagens, objetos, sons, entre outros materiais capazes de proporcionar momentos de prazer, assim como ampliar o universo infantil.

A partir dessas discussões em torno dos diferentes aspectos que envolvem a educação infantil, apontamos a necessidade de planejamentos e propostas intencionais ${ }^{3}$ que abranjam todas as crianças, considerando que estas carregam consigo conhecimentos, identidades e experiências que devem ser reconhecidas e valorizadas no ambiente educacional, independentemente de classe social, raça/etnia, sexo e geração.

\section{Ações Pedagógicas para a Educação das Relações Étnico-Raciais: relatos de uma experiência}

O presente artigo surgiu da experiência realizada no projeto de docência ${ }^{4}$ do curso de Pedagogia da Universidade do Estado de Santa Catarina, ocorrida em uma creche da Rede Municipal de Florianópolis/SC, localizada no bairro Itacorubi. A unidade educativa tem como público-alvo crianças de zero a seis anos, oriundas especialmente do próprio bairro em que se localiza a instituição. No ano de 2010, desenvolvemos ações em um grupo de crianças de quatro e cinco anos de idade. Registramos nove observações participativas, nas quais interagimos com as crianças, os professores/as e funcionários/as, conhecendo a realidade vivenciada pelo grupo, a fim de elaborarmos um projeto de docência que contemplasse todas as crianças. No período de intervenção, praticamos dezesseis atuações, organizadas em sete minioficinas, distribuídas em dois a três dias,

\footnotetext{
${ }^{3}$ Assumimos uma concepção de planejamento fundamentada nas contribuições de Ostetto (2000), que indica a realização de projetos intencionais como modo de planejar as ações da educação infantil com base nas observações dos movimentos do grupo e no registro diário das falas, brincadeiras e atividades das crianças.

${ }^{4}$ Para maiores detalhes, ver: Carvalho, Thaís Regina de; Gaudio, Eduarda Souza. Em busca de novos paradigmas para a educação: Incorporando práticas para a implementação da Lei Federal 10.639/03 na educação infantil. 2010. 84 p. Relatório final de estágio (graduação) - Universidade do Estado de Santa Catarina, Centro de Ciências Humanas e da Educação, Curso de Pedagogia, Florianópolis, 2010.
} 
durante os quais trabalhamos de forma lúdica aspectos da cultura africana e afrobrasileira.

Após análises de pesquisas e alguns debates acerca da implementação do artigo 26-A da LDB (Lei Federal 10639/03), constatamos a dificuldade que muitos/as educadores/as apresentam para planejar e executar ações na perspectiva da Educação das Relações Étnico-Raciais. De acordo com Munanga (2008):

Alguns de nós não receberam na sua educação e formação de cidadãos, de professores e educadores o necessário preparo para lidar com o desafio que a problemática com a convivência da diversidade e as manifestações de discriminação dela resultadas colocam quotidianamente na nossa vida profissional. Essa falta de preparo, que devemos considerar como reflexo do nosso mito de democracia racial compromete, sem dúvida, o objetivo fundamental da nossa missão no processo de formação dos futuros cidadãos responsáveis de amanhã (MUNANGA, 2008, p. 11).

Seguindo esta perspectiva, efetivamos junto ao grupo os seguintes aspectos: identidades, conhecimento do continente africano, máscaras africanas, vestimentas e culinária africana e afro-brasileira, samba, capoeira, bem como as grandes áreas que perpassam a educação infantil, linguagens, brincadeiras, interações, cuidar e educar, procurando reconhecer as crianças como seres ativos, participativos, produtores e transformadores de culturas.

Sobre a constituição da identidade das crianças, Hall (1998) considera que esse processo é marcado por um movimento dialético entre aspectos objetivos e subjetivos, em constantes transformações. Dessa forma, as instituições de educação infantil, responsáveis pela primeira socialização da criança na educação sistemática, precisam levar em consideração as particularidades dos meninos e meninas inseridas em cada contexto social, de modo a problematizar e reconhecer as diferentes populações existentes em nossa sociedade.

Neste sentido, durante este período aspiramos disseminar os diversos elementos pertencentes à cultura afro-brasileira e africana, indo além da fauna e da flora, exibindo as diferentes riquezas que esse continente abriga, pretendendo, assim, auxiliar na 
desconstrução de posturas preconceituosas e discriminatórias, favorecendo a implementação de uma educação das relações étnico-raciais.

Dessa forma, a partir desse tema central, conseguimos envolver diferentes questões fundamentais a serem trabalhadas desde a educação infantil. Entre elas destacamos: múltiplas identidades, fantasias, afetividades, corporeidades, criatividades, assim como um novo olhar sobre a cultura, a história africana e a afro-brasileira. Enfatizamos, assim, as diversas belezas que essas culturas abarcam, além de proporcionar momentos em que as crianças puderam cantar, dançar, brincar, dialogar, expressando suas subjetividades, corporeidades e vivências.

Objetivando contribuir para o processo de concretização de ações que abranjam a diversidade étnico-racial nas instituições de educação infantil, iremos apresentar, a seguir, a organização das ações desenvolvidas junto ao Grupo V (crianças de quatro e cinco anos) de uma creche municipal de Florianópolis/SC. Vale ressaltar, porém, que não estamos expondo essa proposta com o intuito de que ela seja aplicada sem reformulações, isto é, como modelo fechado. Pelo contrário, acreditamos que essas são possibilidades de trabalho, que necessitam ser adequadas e adaptadas, conforme a necessidade de cada grupo. Pretendemos disponibilizar essas informações, com intuito de demonstrar que é possível desenvolver práticas na educação infantil que contemplem as disposições do o artigo 26-A da LDB e das Diretrizes Curriculares Nacionais para a Educação das Relações Étnico-Raciais e para o Ensino de História e Cultura Africana e Afro-Brasileira.

QUADRO 1: ORGANIZAÇÃO DAS AÇÕES REALIZADAS COM CRIANÇAS DE QUATRO E CNCO ANOS

\begin{tabular}{|c|c|c|c|}
\hline $\begin{array}{l}\text { MINIOFICINA } \\
\text { (Temáticas) }\end{array}$ & OBJETIVOS & DURAÇÃO & MATERIAIS \\
\hline $\begin{array}{l}\text { (RE)Conhecendo as } \\
\text { identidades }\end{array}$ & $\begin{array}{l}\text { * Conhecer as diferentes } \\
\text { identidades e } \\
\text { identificações; } \\
\text { * Vivenciar as suas } \\
\text { próprias experiências, } \\
\text { bem como dos/as } \\
\text { amigos/as; } \\
\text { * Manusear e conhecer }\end{array}$ & Dois encontros & $\begin{array}{l}\text { * Objetos que as crianças } \\
\text { possam se identificar; } \\
\text { * Documentos de } \\
\text { identidades; } \\
\text { - Lápis de escrever; } \\
\text { - Lápis de cor; } \\
\text { * Canetinhas; } \\
\text { * Cola. }\end{array}$ \\
\hline
\end{tabular}




\begin{tabular}{|c|c|c|c|}
\hline & $\begin{array}{l}\text { diversos objetos } \\
\text { referentes aos } \\
\text { documentos de } \\
\text { identidades. }\end{array}$ & & \\
\hline $\begin{array}{l}\text { Um novo olhar sobre } \\
\text { o Continente } \\
\text { Africano }\end{array}$ & $\begin{array}{l}\text { Conhecer lugares, } \\
\text { artes, belezas naturais } \\
\text { do Continente Africano; } \\
\text { Desmistificar aspectos } \\
\text { criados em torno da } \\
\text { cultura; }\end{array}$ & Dois encontros & $\begin{array}{l}\text { *lobo; } \\
\text { Baú com imagens do } \\
\text { Continente africano; } \\
\text { Fantoche; } \\
\text { Folha; } \\
\text { Pincel; } \\
\text { - Tintas; } \\
\text { Lápis de cor; } \\
\text { Livro Infantil. }\end{array}$ \\
\hline Máscaras Africanas & $\begin{array}{l}\text { Conhecer como são } \\
\text { feitas e em que } \\
\text { momentos são } \\
\text { utilizadas as máscaras } \\
\text { africanas; } \\
\text { Ampliar os } \\
\text { conhecimentos acerca } \\
\text { da cultura Africana; } \\
\text { Recortar e colar figuras } \\
\text { de revistas; } \\
\text { Construir } \\
\text { coletivamente } \\
\text { materiais; } \\
\text { Assistir contos } \\
\text { africanos. }\end{array}$ & Três encontros & $\begin{array}{l}\text { Máscaras africanas, } \\
\text { feitas de papel micro } \\
\text { ondulado; } \\
\text { Papel micro ondulado; } \\
\text { Palitos de picolé } \\
\text { cortado (representando } \\
\text { a madeira); } \\
\text { Cartolina picada } \\
\text { (representando o } \\
\text { cobre); } \\
\text { Cola; } \\
\text { EVA; } \\
\text { Lápis de Cor; } \\
\text { Canetinhas; } \\
\text { Penas; } \\
\text { Sacos de lixo cortado } \\
\text { em tiras; }\end{array}$ \\
\hline $\begin{array}{l}\text { Vestimentas } \\
\text { Africanas e Afro- } \\
\text { brasileiras }\end{array}$ & $\begin{array}{l}\text { Conhecer as } \\
\text { vestimentas africanas; } \\
\text { Ampliar os } \\
\text { conhecimentos acerca } \\
\text { da cultura Africana; } \\
\text { * Construir materiais; } \\
\text { Ampliar vocabulário; } \\
\text { Ouvir histórias; }\end{array}$ & Dois encontros & $\begin{array}{l}\text { Abadás; } \\
\text { Tecidos Crus; } \\
\text {. Fantoche; } \\
\text { Tintas; } \\
\text {. Lincel; } \\
\text {. Bivro Infantil; } \\
\text { micro ondulado; } \\
\text { Barbante; }\end{array}$ \\
\hline
\end{tabular}




\begin{tabular}{|c|c|c|c|}
\hline & & & $\begin{array}{l}\text { Lápis de cor; } \\
\text { Canetinhas. }\end{array}$ \\
\hline $\begin{array}{l}\text { Culinária Africana e } \\
\text { Afro-Brasileira }\end{array}$ & $\begin{array}{l}\text { Conhecer algumas } \\
\text { plantações africanas; } \\
\text { Ampliar os } \\
\text { conhecimentos acerca } \\
\text { da cultura Africana; } \\
\text { * Trabalhar com a terra; } \\
\text { Plantar sementes. }\end{array}$ & Três encontros & $\begin{array}{l}\text { Sementes de milho; } \\
\text { Agua; } \\
\text { Terra; } \\
\text { Recipiente para } \\
\text { plantação; } \\
\text { Ingredientes para bolo } \\
\text { de milho; } \\
\text { Bingo das culinárias; } \\
\text { Figuras com pratos da } \\
\text { culinária africana e afro- } \\
\text { brasileira; } \\
\text { Loucinhas; } \\
\text { Caixas de papelão } \\
\text { (Simulação de fogão). }\end{array}$ \\
\hline Samba & $\begin{array}{l}\text { Ampliar o repertório } \\
\text { musical; } \\
\text { Conhecer } \\
\text { personalidades do } \\
\text { samba; } \\
\text { * Ampliar vocabulário; } \\
\text { Conhecer os } \\
\text { instrumentos musicais; } \\
\text { Trabalhar } \\
\text { corporeidades; } \\
\text { Construir materiais } \\
\text { coletivamente }\end{array}$ & Dois encontros & $\begin{array}{l}\text { CD; } \\
\text { - Instrumentos musicais; } \\
\text { Latinhas; } \\
\text { Garrafinhas } \\
\text { * Milho; } \\
\text { Feijão e pedrinhas; } \\
\text { Tintas; } \\
\text { Imagens de } \\
\text { personalidades do } \\
\text { - Pamba; } \\
\text { - Canetinhas. }\end{array}$ \\
\hline Capoeira & $\begin{array}{l}\text { Ampliar o repertório } \\
\text { musical; } \\
\text { conhecer aspectos da } \\
\text { capoeira; } \\
\text { * Ampliar vocabulário; } \\
\text { Conhecer os } \\
\text { instrumentos musicais; } \\
\text { Trabalhar } \\
\text { corporeidades; } \\
\text { Construir materiais } \\
\text { coletivamente. }\end{array}$ & Dois encontros & $\begin{array}{l}\text { *ídeo sobre capoeira; } \\
\text { *axixi; } \\
\text { * } \text { Perimbau; } \\
\text { E.V.A.; } \\
\text { * Lápis de cor; } \\
\text { * Ciz de cera; } \\
\text { *antejoulas; } \\
\text { *apel crepom; } \\
\text { Palitos de picolé. }\end{array}$ \\
\hline
\end{tabular}

FONTE: CARVALHO; GAUDIO, 2010.

Após expor as temáticas, objetivos, duração e materiais utilizados durante as minioficinas com as crianças, salientamos que a efetivação de práticas que contemplam a 
diversidade étnico-racial deve ser compreendida para além de projetos isolados, integrando assim os projetos político-pedagógicos, planejamentos, reuniões pedagógicas, enfim, o cotidiano das instituições de educação infantil. Portanto, essas ações podem ser desenvolvidas no decorrer do ano, não necessitando seguir a organização e a sequência adotada e sim ser trabalhadas de acordo com os assuntos que o grupo vem explorando.

Dentre as intervenções apresentadas anteriormente, destacamos que uma atividade essencial a ser realizada com as crianças é o trabalho com as identidades. Com esta ação, podemos proporcionar à criança (re) que se conheça a si e ao outro, tendo a oportunidade, por meio do diálogo, de expressar suas experiências e conhecimentos, bem como apreciar as vivências dos seus pares. Para isso, foram-lhes propostas, durante a minioficina, situações em que falaram sobre o seu jeito de ser, assim como sobre suas características físicas, ou seja, suas identidades:

* "Letícia", sou morena, tenho olho preto, cabelo preto, e gosto de brincar e de ler livros".

* “O meu nome é João Victor, sou loiro, meu cabelo é loiro, e meu olho é qual prof? É castanho claro. E eu gosto de brincar e de vim pra Creche".

* "Eu sou Clarice, sou morena, mas minha pele é bem clarinha, e o meu cabelo é marrom e meu olho também. Eu gosto de brincar, de ficar em casa com minha mãe e de contar historinhas".

* "Meu nome é Guilherme, eu sou pequenininho, moreno e tenho olho marrom. Eu gosto dos meus amiguinhos, de vim pra creche e de brincar com meu boneco" (Diário de Campo do dia 26/8/10).

Por meio dessa ação, ainda conseguimos explorar questões de gênero, de corporeidades, de preferências, de afetividades e de subjetividades, permitindo, assim, a valorização de todas as culturas. Isso porque:

A criança que vivencia situação semelhante de discriminação com relação ao seu corpo pode não construir uma imagem positiva de si mesma. Os referenciais da criança negra a respeito de seu corpo, cor da pele, tipo de cabelo, devem ser modificados para que seja aceita por colegas e

\footnotetext{
${ }^{5}$ Os nomes utilizados são fictícios para preservar a identidade das crianças.
} 
educadoras desconsiderando-se assim a sua história, sua cultura (SANTANA, 2006, p. 45).

Partindo do pressuposto de que as imagens veiculadas sobre o continente africano são reduzidas, não contemplando a diversidade cultural existente nos países africanos, torna-se primordial o desenvolvimento de ações que ampliem e desmistifiquem esse tipo de preconceito. Sendo assim, uma proposta a ser efetivada é a exibição de aspectos positivos acerca da cultura africana e da afro-brasileira. Por meio da exposição de diferentes elementos existentes nessa cultura, contribuiremos para a diminuição de visões estereotipadas e estigmatizadas, assim como para seu conhecimento e valorização.

Seguindo esta perspectiva, destacamos a importância de pesquisar e explicitar as diferentes riquezas e belezas existentes no continente africano, não as reduzindo, nem demonstrando posturas etnocêntricas a fim de construir um novo olhar sobre o continente africano. Dentre esses aspectos, citamos: os diferentes dialetos, as máscaras africanas, vestimentas, culinária, danças, contos e lendas africanas, artesanatos, religiosidades, brincadeiras, ritmos e instrumentos, entre outros encantos.

Para ilustrar, destacamos a ação desenvolvida no grupo citado, com a qual, a partir das informações que envolvem máscaras e vestimentas africanas. Almejamos aguçar a curiosidade, a criatividade e a imaginação das crianças, ampliando seu conhecimento, proporcionando-Ihes a experimentação de diferentes materiais.

Além disso, durante a experiência de estágio de docência ressaltamos outros aspectos afro-brasileiros como: o samba, a capoeira, a culinária, danças, religiões, músicas, instrumentos, entre outros. Nestes momentos, as crianças tiveram a oportunidade de exporem suas experiências, proporcionando valorização e reconhecimento à sua cultura, tornando-se assim, sujeitos participativos no processo educacional.

Em meio às ações desenvolvidas na instituição mencionada, enfatizamos que é primordial o trabalho com o samba, a capoeira e a culinária. Através dessas propostas, expandimos o repertório das crianças, proporcionando-lhes a ampliação dos diferentes 
conhecimentos da história e cultura africana e afro-brasileira, contribuindo para a efetuação de uma educação que contemple as diferentes culturas. Nessa discussão, Santos (2001) denuncia:

Ainda que a escola sozinha não seja capaz de reverter anos de desqualificação da população negra e supervalorização da população branca, ao longo prazo ela pode desempenhar um importante papel na construção de uma nova cultura, de novas relações que vão além do respeito às diferenças. Possibilitando que todas as vozes possam ecoar no espaço escolar, chegar-se-à consciência de que é na diversidade que se constrói algo novo (SANTOS, 2001, p. 102).

Neste sentido, vale destacar as múltiplas estratégias a serem utilizadas no desenvolvimento desses trabalhos, entre elas teatros de fantoches, dramatizações, vídeos infantis e contação de histórias. Sobre esse assunto, Abromovich (1994, p. 16) expõe que "[...] é importante para a formação de qualquer criança ouvir muitas, muitas histórias"... escutá-las é o início da aprendizagem para ser um leitor, e ser leitor é ter um caminho absolutamente infinito de descoberta e de compreensão de mundo.

Por isso, acreditamos que a contação de histórias é essencial no período da infância, pois, através delas, as crianças, além de ampliar seus vocabulários por meio das palavras que aparecem no decorrer do texto, descobrem e conhecem outros lugares e tempos existentes. Assim, entendemos que a contação de histórias é de suma importância para o desenvolvimento de todas as crianças. Fato que reitera a necessidade de uma seleção atenta das estórias e imagens a serem apresentadas, visto que por meio delas as crianças também iniciam o processo de construção das identidades e autoimagem.

Finalizando a exposição das ações, salientamos que através desse trabalho podemos oportunizar as crianças a experimentação de diversos materiais e momentos, entre elas: pinturas, recorte e colagem, construção de materiais coletivos e individuais, desenhos, brincadeiras, montagens, jogos, entre outras manifestações.

A partir dessa proposta reiteramos a necessidade de as instituições de educação infantil também contarem com ações intencionais que tenham como premissa combater 
o racismo, os preconceitos e as discriminações, além de ampliar os conhecimentos das crianças acerca da cultura africana e afro-brasileira, proporcionando assim a concretização de uma Educação das Relações Étnico-Raciais.

\section{Considerações finais}

Conforme as Diretrizes Curriculares Nacionais para a Educação das Relações Étnico-Raciais e para o Ensino de História e Cultura Africana e Afro-Brasileira (2005):

É importante destacar que não se trata de mudar um foco etnocêntrico marcadamente de raiz européia por um africano, mas de ampliar o foco dos currículos escolares para a diversidade cultural, racial, social e econômica brasileira. Nesta perspectiva, cabe à escola incluir no contexto dos estudos e atividades, que proporciona diariamente, também as contribuições históricoculturais dos povos indígenas e dos descendentes de asiáticos, além das de raiz africana e européia. É preciso ter clareza que o Art. $26^{\text {a }}$ acrescido à Lei 9394/1996 provoca bem mais do que inclusão de novos conteúdos: exige que se repensem relações étnico-raciais, sociais, pedagógicas, procedimentos de ensino, condições oferecidas para a aprendizagem, objetivos tácitos e explícitos da educação oferecida pelas escolas (BRASIL, 2005, p. 17).

Face ao disposto, reiteramos a necessidade de no momento do planejamento considerar todas as crianças na sua plenitude. Reconhecemos que essas ações ainda necessitam de muitas discussões e aprofundamentos, assumindo uma postura comprometida com a educação das relações étnico-raciais.

Ao finalizar essa proposta, esperamos contribuir na formação inicial e continuada dos/as educadores/as para que, a partir dessa experiência os/as mesmos/as se sintam incentivados/as e encorajados/as a efetivar ações que buscam auxiliar na desconstrução de práticas homogeneizadoras que contemplam apenas uma parcela da sociedade.

Dessa forma, no presente artigo, listamos diversos elementos, que os/as professores, gestores/as e demais envolvidos/as com a educação poderão explorar de forma engajada, desenvolvendo, assim, trabalhos intencionais e comprometidos com a educação das relações 
étnico-raciais, contribuindo para a construção de uma sociedade menos excludente e discriminatória.

\section{Referências bibliográficas}

ABRAMOVICH, F. Literatura Infantil. Ouvindo Histórias. ed. 4. São Paulo: Scipione, 1994.

ABRAMOWICZ, Anete. A pesquisa com crianças em infâncias e a sociologia da infância. In: FARIA, Ana Lúcia Goulart de.; FINCO, Daniela. (Orgs.). Sociologia da infância no Brasil. Campinas, SP: Autores Associados, 2011. p. 17-36.

BORGES, M.K.; FONTANA, K.B.; ROESLER, J. SARTORI, A.S. In: Caderno Pedagógico Tecnologia, Educação e Aprendizagem. Florianópolis: UDESC/CEAD, 2003.

BOTEGA, Gisely Pereira. As relações raciais nos contextos educativos: suas implicações na constituição do autoconceito das crianças negras moradoras da comunidade de santa cruz do município de Paulo Lopes/SC. 2006. Dissertação (Mestrado em Educação) - Universidade Federal de Santa Catarina - Florianópolis/SC.

BRASIL. Ministério da Educação. Diretrizes Curriculares Nacionais para a Educação das Relações Étnicorraciais e para o Ensino de História e Cultura Africana e Afrobrasileira. Brasília: MEC, 2005.

1996.

. Ministério da Educação. Lei de Diretrizes e Bases da Educação Nacional. Brasília: MEC, . Orientações e ações para a educação das relações étnico-raciais. Brasília: SECAD, 2006

CAVALLEIRO, Eliane. Racismo e anti-racismo na educação: repensando nossa escola. São Paulo: Selo Negro, 2001.

; GAUDIO, Eduarda Souza. Em busca de novos paradigmas para a educação: Incorporando práticas para a implementação da Lei Federal 10639/03 na educação infantil. 2010. Relatório final de estágio (Graduação) - Universidade do Estado de Santa Catarina - Centro de Ciências Humanas e da Educação - Curso de Pedagogia - Florianópolis. 
CORSINO, Patrícia. Linguagem na Educação Infantil: as brincadeiras com as palavras e as palavras como brincadeira. In: BRASIL. Ministério da Educação. O cotidiano na Educação Infantil. Boletim 23. 2006. p. $28-46$.

DIAS, Karina Sperle. Formação Estética: em busca do olhar sensível. In: KRAMER, Sônia; LEITE, Maria Isabel; NUNES, Maria Fernanda. (Orgs.). Infância e Educação Infantil. Campinas: Papirus, 1999. (Coleção Prática Pedagógica) 1999. p. 175 - 201.

FLORIANÓPOLIS. Prefeitura Municipal de Educação de Florianópolis. Diretrizes educacionais pedagógicas para a educação infantil. Secretaria Municipal de Educação. Florianópolis: Prelo Gráfica \& Editora Ltda., 2010.

HALL, Stuart. A identidade cultural na pós-modernidade. Rio de Janeiro: DP\&A, 1998.

LIMA, Maria Batista. Práticas cotidianas e identidades étnicas: Um estudo no contexto escolar. 2006. Tese (Doutorado em educação) - Pontifícia Universidade Católica do Rio de Janeiro - Rio de Janeiro.

MELLO, Suely. Infância e humanização: algumas considerações na perspectiva histórico-cultural. Revista Perspectiva: Revista do Centro de Ciências da Educação. Florianópolis. V. 25, n.1. Jan/jun. 2007, p. $83-104$.

MUNANGA, Kabengele. (Org). Superando o racismo na escola. Ministério da Educação, Secretaria de Educação Continuada, Alfabetização e Diversidade. Brasília, 2008.

NASCIMENTO, Maria Letícia Barros Pedroso. Reconhecimento da sociologia da infância como área de conhecimento e campo de pesquisa: algumas considerações. In: FARIA Ana Lúcia Goulart de; FINCO, Daniela. (Orgs.) Sociologia da infância no Brasil. Campinas, SP: Autores Associados, 2011, p. $37-52$.

OLIVEIRA, Fabiana de. Um estudo sobre a creche: o que as praticas educativas produzem e revelam sobre a questão racial? 2004. Dissertação (Mestrado em Educação), Universidade Federal de São Carlos. São Carlos/SP.

OSTETTO, Luciana Esmeralda. Planejamento na educação infantil: mais do que a atividade, a criança em foco. In: OSTETTO, Luciana Esmeralda. (Org.). Encontros e Encantamentos na Educação Infantil: Partilhando experiências de estágios. Campinas, SP: Papirus, 2000, p. 89-102. 
SANTANA, Patrícia Maria de Souza. Educação Infantil. In: Ministério da Educação/ Secretaria da Educação Continuada, Alfabetização e Diversidade. Orientações e Ações para a Educação das Relações Étnico-Raciais. Brasília: SECAD, 2006, p. 25 - 49.

VIGOTSKI, L. S. Imaginação e criação na infância. São Paulo: Ática, 2009.

Recebido em: 25/02/2013

Aprovado em: 23/04/2013

Universidade do Estado de Santa Catarina - UDESC

Centro de Ciências Humanas e da Educação - FAED

Revista PerCursos

Volume 14 - Número 26 - Ano 2013 revistapercursos@gmail.com 